\title{
Çevrimiçi Oyunların Tatil Satın Alma Niyetine Etkisi
}

\author{
The Effect of Online Games on Vacation Purchase Intention
}

\author{
Yasin Emre OĞUZ*, Mustafa Çağatay KIZILTAŞ **, Veysel YILMAZ*** \\ * (Sorumlu Yazar), Arş. Gör, Eskişehir Osmangazi Üniversitesi Turizm Fakültesi, Meşelik Kampüsü, Prof. Dr. Nabi Avcı Bulvarı No: 4, 26040, Odunpazarı, Eskişehir. \\ E-posta: yeoguz@ogu.edu.tr \\ ORCID: 0000-0002-2139-4278 \\ ** Öğr, Gör., Sivas Cumhuriyet Üniversitesi, Otel, Lokanta ve İkram Hizmetleri, Divriği Nuri Demirağ Meslek Yüksekokulu, Selavattepe Mevkii, 58300, Divriği, \\ Sivas. \\ E-posta: cagataykzlts@cumhuriyet.edu.tr \\ ORCID: 0000-0003-2194-6041 \\ *** Prof. Dr., Eskişehir Osmangazi Üniversitesi Fen Edebiyat Fakültesi, Meşelik Kampüsü, Prof. Dr. Nabi Avcı Bulvarı No:4, 26040, Odunpazarı, Eskişehir. \\ E-posta: vyilmaz@ogu.edu.tr \\ ORCID: 0000-0002-3249-8961
}

\section{MAKALE BILGILERI}

Makale işlem bilgileri:

Gönderilme tarihi: 15 Nisan 2021

Düzeltme: 21 Haziran 2021

Düzeltme: 27 Temmuz 2021

Düzeltme: 7 Eylül 2021

Kabul: 214 Eylül 2021

Anahtar sözcükler: Çevrimiçi oyunlar, Tatil satın alma niyeti, Yapısal eşitlik modellemesi.

\section{ARTICLE INFO}

Article history:

Submitted: 15 April 2021

Resubmitted: 21 June 2021

Resubmitted: 27 July 2021

Resubmitted: 7 September 2021

Accepted: 14 September 2021

Key words: Online games, Vacation purchase intention, Structural equation modeling.

\begin{abstract}
ÖZ
Teknolojide yaşanan ilerlemeler ile birlikte çevrimiçi oyun endüstrisi de son yıllarda ciddi bir gelişim göstermiştir. Özellikle Covid-19 pandemisi döneminde karantina süreçlerinin başlamasılyla birlikte çevrimiçi oyunlara olan ilgi daha da artmış ve dünya genelinde çevrimiçi oyuncu sayısı yaklaşık 2,6 milyara ulaşmıştır. Çevrimiçi oyunlar içerisinde birebir aynı veya çok benzer șekilde gerçek mekanlar da kullanılmaktadır. Bu araștırmanın çıkış noktasını da çevrimiçi oyunlarda yer alan gerçek mekanların yarattığı deneyimin, çevrimiçi oyunlar üzerinden kurulan iletişimin ve çevrimiçi oyun bağımlıı̆ıının tatil satın alma niyeti yaratıp yaratmadığının incelenmesi olușturmaktadır Nicel yöntemin kullanıldığı bu araștırmada veriler anket tekniği ile toplanmıștır. Alanyazında yer alan çalışmalara dayanan anket formu 750 katılımcıya uygulanmıştır. Araştırmanın ilk bölümünde ilgili alanyazın taranmış, ikinci bölümünde ise yapısal eşitlik modellemesi kurularak ilişkiler incelenmiștir. Araștırma sonucunda çevrimiçi oyunlara yönelik iletișim, bağımlılık ve deneyim faktörlerinin tatil satın alma niyeti üzerinde istatistiksel olarak anlamlı ve pozitif yönlü bir etkisi olduğu tespit edilmiștir. Buradan hareketle önerilen model kabul edilmiştir.
\end{abstract}

\begin{abstract}
Advancements in technology have also influenced the game industry. Especially Covid-19 restrictions forced people to stay home and this lead to an increase in the interest in online games. As a result of this, it is estimated that there are 2,6 billion gamers throughout the world. Online games usually contain the structure of real places or metaverses. Therefore, this study focuses on the influence of real place experiences, communication and addiction in online games on users' intention to purchase a vacation. The study utilized a quantitative method and data was collected through a survey. A questionnaire form derived from previous literature was filled by 750 participants. A literature review was conducted in the first part of the study. In the second part relationships between variables are examined through the structural equation method. Findings revealed that communication, addiction and experience factors have a significant positive impact on vacation purchase intention. Therefore, the proposed model was accepted.
\end{abstract}

\section{GiRiş}

21. yüzyıl ile birlikte teknoloji radikal bir şekilde değişim ve gelişim göstermiştir. Bu değişim ve gelişim sonucu ortaya çıkan teknolojik devrim, tüm sektörler üzerinde etkili olmuştur. Bu sektörlerden biri de turizm sektörüdür. Teknolo- jide yaşanan gelişimler turizm işletmeleri ve tüketiciler arasındaki etkileşimi desteklemekte ve destinasyonların yönetim ve pazarlama süreçlerinin yeniden düzenlenmesine neden olmaktadır (Buhalis ve Law 2008). Özellikle internetin yaygınlaşması tüketicilerin sosyalleşme ve eğlenme 
davranışlarını da etkilemiş ve bu davranışlarda değişiklikler meydana getirmiştir (Dindar ve Akbulut 2014). İnternetin her eve girmesi ile birlikte dünyanın her yerinden insanlar arasında bağlantı ve etkileşim de artış göstermiştir. Ayrıca sanal gerçeklik ve artırılmış gerçeklik gibi teknolojiler de insanların internet aracılığıyla yapabildikleri deneyimlerin ve etkileşimlerin sayısını artırmıştır (Yung ve Khoo-Lattimore 2020). Bu etkileşimlerden biri de çevrimiçi oyunlar aracılığıyla gerçekleşen etkileşimdir. Çevrimiçi oyunlar sadece kullanıcılar arasında popüler olmakla kalmayıp izleyiciler açısından da bir piyasa oluşturmayı başarmıştır. Bunun en önemli nedeni çevrimiçi oyunların aynı zamanda e-spor türü içinde de değerlendirilmesidir. E-spor elektronik sporun kısaltması olarak kullanılmaktadır. E-spor genellikle farklı oyunlar, aşamalar, ligler ve turnuvalar tarafından organize edilen ve oyuncuların genellikle çeşitli ticari kuruluşlar tarafından desteklendiği profesyonel veya amatör olarak gerçekleştirilen çevrimiçi oyunları kapsamaktadır (Hamari ve Sjöblom 2017). E-spor diğer spor dallarında olduğu gibi gerçeğe yakın bir rekabet deneyimi sunmaktadır. Bu nedenle de özellikle gençler arasında oldukça popüler bir rekreasyonel aktivite haline gelmiştir (Adamus 2012: 477).

E-spor da futbol, basketbol, voleybol, tenis, yüzme gibi geleneksel sporlara benzer şekilde çeşitli organizasyonlara, liglere ve turnuvalara sahiptir. Yine geleneksel sporlarda olduğu gibi oyuncular bu aktivitelerden para da kazanmaktadır. Gençlerin de yoğun ilgisi ile birlikte e-spor endüstrisi günden güne küresel hale gelen büyük bir endüstri olarak ifade edilmektedir (Hamari ve Sjöblom 2017). Ayrıca e-spor endüstrisine yapılan sponsorluk meblağları geleneksel sporlarla da rekabet edebilir bir seviyeye ulaşmıştır. Bu popülerliğin ise sürekli bir biçimde artarak devam edeceği ön görülmektedir (Chen 2015). Çevrimiçi oyunlar dünya çapında sanal olarak bağlantıların ve arkadaşlıkların kurulması anlamında farklı bölgelerden milyonlarca kullanıcıya ev sahipliği yapmaktadır. Bu nedenle hem önemli bir rekreasyon aktivitesi (Trepte, Reinecke ve Juechems 2012) hem de sanal dünyadaki en popüler eğlence uygulaması olarak kabul edilmektedir (Chen 2010).
2020 yılı itibariyle dünya genelinde yaklaşık olarak 2,6 milyar kişinin çevrimiçi oyun oynadığı bilinmektedir (Statista 2020). Bu sayı yaklaşık olarak dünya nüfusunun üçte birine karşılık gelmektedir. Bu araştırmada da çevrimiçi oyunlarda kullanılan gerçek veya gerçeğinden ilham alınmış mekânların yarattığı deneyim hissinin, çevrimiçi oyunlar üzerinden kurulan iletişimin ve çevrimiçi oyun bağımlılığının tatil satın alma niyeti yaratıp yaratmadığı sorusuna cevap aranmaktadır. Özellikle gerçek destinasyonlardan yararlanılarak oluşturulan oyun haritalarının, oyuncuların bu bölgelere yönelik ziyaret etme niyetlerine etkileri incelenmiştir. Alanyazın incelendiğinde çevrimiçi oyunların turizme etkileri ile ilgili çok fazla çalışma olmadığı görülmüştür. $\mathrm{Bu}$ araştırmayla da alanyazındaki bu boşluk doldurulmaya çalışılmıştır. Ayrıca bu durum hem araştırmanın önemini hem de özgün değerini oluşturmaktadır.

\section{KURAMSAL ÇERÇEVE}

Araştırmanın kuramsal çerçeve başlığı altında öncelikle çevrimiçi oyunlar ve tatil satın alma niyeti kavramları açıklanmıştır. Devamında hipotezler ve araştırma modeli üzerinde durulmuştur.

\section{Çevrimiçi Oyunlar}

Çevrimiçi oyunlar, genellikle kullanıcıların hayal kurmalarını ve eğlenmelerini sağlayan çok oyunculu ve internet tabanlı oyunlar olarak ifade edilmektedir. Çevrimiçi oyunların en önemli özelliği fiziksel olarak aynı ortamda bulunmayan dünyanın dört bir yanından insanların arasında bir iletişim yaratmasıdır (Lee 2009). 2000'li yılların başından beri küresel anlamda hızla büyüyen oyunlar ve oyun şirketleri ilk zamanlarında sadece belirli yaş grubuna hitap eden bir eğlence faktörü olarak kabul edilmekteydi (Lee vd. 2004). Ancak günümüzde dünyanın her yerinden ve her yaş grubundan insan tarafından rağbet gören bir hal almıştır (Liao vd. 2020). Hızla büyüyen çevrimiçi oyun sektörü kısa zamanda milyar dolarlık bir sektör haline gelmiştir (Meagher ve Teo 2005: 457). Günümüzde ise bu artış daha da hızlanmış bir durumdadır. Çevrimiçi oyunlar artık bir kül- 
tür haline gelmiş (Reer ve Krämer 2014; Gong vd. 2020) ve en popüler rekreasyon aktivitesine dönüşmüştür (Chen 2010; Deleuze vd. 2017).

Çevrimiçi oyunların bir fenomen haline dönüşmesi oyuncuların yanı sıra izleyicilerin sayısının da artmasını sağlamıştır (Hyeong vd. 2020). Bilgisayarlar ve mobil telefonlar vasitasiyla internet tabanlı oynanan oyunlar oyun firmalarının piyasa değerlerini de ciddi şekilde artırmıştır (Hsu ve Lu 2004; Gray vd. 2018). Son y1llarda en büyük eğlence sektörü haline gelen çevrimiçi oyun endüstrisi, müzik ve sinema endüstrilerini geride bırakarak yaklaşık olarak 21 milyar dolarlık bir gelir hacmine ulaşmıştır (Statista 2020). Böylece kâr potansiyeli yüksek olan bir sektör haline de gelmiştir (Lee vd. 2004; Teng 2017).

Yaygın olarak oyuncuların birbiriyle bireysel ve takım halinde rekabet etmesine olanak sağlayan çevrimiçi oyunlar kendi içerisinde de farkl1laşmaktadır (Hsu ve Lu 2004). Bunların başında birinci şahıs nişancı (FPS) oyunları olarak adlandirılan CS:GO, Valorant ve PUBG gibi oyunlar; çok oyunculu savaş arenası (MOBA) oyunları olarak adlandırılan League of Legends ve Dota gibi oyunlar; çok katılımcılı çevrimiçi rol yapma oyunu (MMORPG) olarak adlandirılan Silkroad Online ve Knight Online gibi oyunlar ve spor oyunları olarak kabul edilen FIFA, PES ve NBA gibi oyunlar gelmektedir. Takım halinde rakip takımın karargahını yok etmeyi amaçlayan MOBA oyunları genelde yoğun rekabete dayanmaktadır fakat oyun süreleri diğer türlere göre daha kısadır (Deleuze vd. 2017; Funk, Pizzo ve Baker 2018). En ünlü MOBA oyunu olan League of Legends dünya genelinde yaklaşık olarak 115 milyon aktif kullanıcıya sahiptir. MMORPG ve FPS oyuncularının oyun oynamaya harcadıkları süreler oldukça fazladır. Spor oyunlarında da geleneksel veya modern sporlar simülasyon sayesinde oynanabilmektedir. Burada da amaç rakiple mücadele ederek ona karşı üstün gelmektir (Jonasson ve Thiborg 2010).

MMORPG türü oyunlar çevrimiçi oyun endüstrisinin en hızlı gelişim gösteren çeşitlerinden biri olarak kabul edilmektedir (Peng, Sun ve Wu 2009). Dünya çapında milyonlarca oyuncu tarafından kullanılan popüler bir eğlence ve rekreasyon aktivitesi olarak ifade edilmektedir (Hussain, Williams ve Griffiths 2015). Katılımc1lar açısından dijital bir eğlence tarzı haline gelen bu oyun türü (Hsu, Wen ve Wu 2009) karşılıklı ilişkiler ve etkileşim üzerine kuruludur (Choi vd. 2007). Kullanıcı sayısı 50 Milyondan fazla olan bu oyun (Badrinarayanan, Sierra ve Martin 2015), insanların zamanının önemli kısmını geçirdikleri bir fenomen haline gelmiştir (Dindar ve Akbulut 2014). FPS oyunları, oyuncunun ana karakterinin bakış açısını ele aldığı, birinci şahıs nişancı oyunudur. Genelde takım olarak oynanan FPS oyunlarda eylem silahlar üzerinde merkezlenmektedir. Oyuncunun oyunu kazanabilmesi için farklı türde görevleri yerine getirmesi gerekmektedir. Bu görevler rakip takım oyuncularını öldürmek ya da karşı takım oyuncularının görevlerini yerine getirmesini engellemeye çalışmaktır. Bunu yaparak oyuncu diğer oyuncularla rekabet edebilmektedir (Jonasson ve Thiborg 2010; Kindermann, Javor ve Reuter 2016; Deleuze vd. 2017; Lacka 2020). Çevrimiçi oyunlar ile ilgili alanyazın incelendiğinde çevrimiçi oyunlara yönelik tüketici algılarının genellikle üç boyut altında toplandığı görülmüştür. Bu kavramlar çevrimiçi oyunlardan elde edilen deneyim, çevrimiçi oyunlarla birlikte gelişen iletişim ve çevrimiçi oyun bağımlılığıdır.

\section{Tatil Satın Alma Niyeti}

Araştırma kapsamında üzerinde durulan diğer kavram ise tatil satın alma niyetidir. Satın alma niyeti bir ürün veya hizmetin gelecekte satın alınması kararını ifade eden soyut bir kavramdır. Bu soyut özellik nedeniyle satın alma niyeti çeşitli faktörlerden etkilenmektedir. Bu faktörlerin başında tutum, algılanan kalite ve ürünün özellikleri gelmektedir. Alanyazın incelendiğinde genellikle satın alma niyetine yönelik olarak yapılan çalışmaların algılanan risk, marka imajı, tutum, işletme imajı, hizmet kalitesi gibi değişkenler üzerinden incelendiği görülmüştür $(\mathrm{Wu}$, Yeh ve Hsiao 2011).

Günümüz toplumunda internet kullanımının daha da artması ile birlikte turizm endüstrisi de potansiyel müşteriler ile bağlantı kurma, turistik ürün ve hizmet sunma şeklinde değişiklikle- 
re gitmek zorunda kalmıştır. Özellikle çevrimiçi sosyal kanallar aracılığıyla insanların turizm ürün ve hizmetlerini satın alma ve tüketme şekillerinde büyük değişiklikler yaşanmıştır (Pietro ve Pantano 2013). Oyun endüstrisinde yaşanan gelişmeler ile birlikte sanal deneyimlerini gerçek bir deneyime dönüştürmek isteyen oyuncuların tatil satın almaya yönelik ilgilerinin de arttığ görülmüştür. Özellikle son yıllarda yaygınlaşan sanal gerçeklik ve artırılmış gerçeklik teknolojilerinin hem oyunlarla hem de turizmle buluşması çevrimiçi oyunların turizme etkilerini de merak edilir bir hale getirmiştir (Lacka 2020; Yung ve Khoo-Lattimore 2020). Bu araştırmada da tatil satın alma niyeti çevrimiçi oyunlara yönelik bağımlılık, iletişim ve deneyim üzerinden incelenmiştir.

\section{Araştırma Modeli ve Hipotezler}

İnternet kullanımının yaygınlaşması ve kullanıcı sayısında yaşanan artışlar nedeniyle önemi daha da artan çevrimiçi oyunlar satın alma niyeti ile ilgili akademik çalışmalara da konu olmaya başlamıştır. Bilgisayar oyunların tüketici kararlarına etkileri ile ilgili yapılan ilk çalışmalardan biri Zeren ve Paylar'a (2016) aittir. Bu araştırmada ürün yerleştirilmesi yapılan bir bilgisayar oyununun markaların hatırlanma durumuna ve bunun tüketicilerin tutum ve satın alma niyetlerine etkileri incelenmiştir. Araştırma sonucunda oyun içerisinde gördükleri markaların tüketicilerin markalara yönelik satın alma niyetini etkilediği belirlenmiştir. Özellikle oyunda geçirilen sürenin artmasının oyuncuların satın alma niyetleri üzerine etkili olduğu tespit edilmiştir. Çevrimiçi oyunlar ile ilgili önemli bir nokta da yarattıkları bağımlılıklardır. Bu kapsamda Balakrishnan ve Griffiths (2018) tarafından yapılan araştırmada çevrimiçi mobil oyunlara yönelik bağımlılı̆̆ın oyun içi uygulamaları satın alma niyetine etkileri incelenmiştir. Araştırma sonucunda çevrimiçi mobil oyunlara yönelik bağımlılık ile uygulama için satın alma niyetleri arasında pozitif yönlü bir ilişki olduğu belirlenmiştir. Buradan hareketle aşağıdaki hipotez geliştirilmiştir:

$H_{1}$ : Çevrimiçi oyun bağımlılı̆̆ının tatil satın alma niyetine pozitif yönlü bir etkisi vardir.
Çevrimiçi oyunlar ile ilgili temel noktalardan biri de çevrimiçi oyunlardan sağlanan iletişimdir. Çevrimiçi oyun oynayan çoğu kullanıcının temel motivasyonu arkadaşlık ilişkileri geliştirmek ve diğer insanlarla iletişim sağlamaktır (Deleuze vd. 2017). Çevrimiçi oyunlar toplumda popülerlik kazandığından beri etkileşim, sosyalleşme ve ilişki geliştirme aracı olarak kabul edilmektedir. Çevrimiçi oyun oyuncuları, ortak hedeflere ulaşmak için birbirleriyle aktif olarak iletişim ve iş birliği yapma eğilimindedir ve bu sayede oyuncular arasında güçlü bağların oluşması sağlanmiş olur (Shin, Jeong ve Park 2021). Büyükbaykal ve Cansabuncu (2020), yaptıkları çalışmada yeni medya ve iletişim teknolojisi olarak çevrimiçi oyunların ortaya çıktığını ve çevrimiçi oyunların yeni medyanın önemli iletişim ortamlarından birini oluşturduğunu savunmuşlardır. Bu kapsamda da aşağıda yer alan hipotezler kurulmuştur:

\section{$\mathrm{H}_{2}$ : Çevrimiçi oyunlar aracılı̆̆ıyla sağlanan iletişimin tatil satın alma niyetine pozitif yönlü bir etkisi vardir.}

Çevrimiçi oyunlarla alakalı önemli bir durum da oyuncuların yaşadıkları deneyimlerdir. Çevrimiçi oyunlarda kullanılan mekânlarda gerçek veya gerçeğinden ilham alınmış şehirler veya bölgeler de kullanılmaktadır. Ayrıca ürün yerleştirme olarak ifade edilebilen ve bilinç altı mesajlarla satın alma kararını etkileyen reklamlar da çevrimiçi oyunlarda sıklıkla kullanılmaktadır. Bu konuda bir araştırmada oyunlara yapılan ürün yerleştirmeler ve bunun tüketicilerin satın alma davranışına etkileri incelenmiştir. Araştırma sonucunda bilgisayar oyunlarına ürün yerleştirme yapılması ile satın alma davranışı arasında pozitif yönlü ve istatistiksel olarak anlamlı bir ilişki olduğu tespit edilmiştir (Alagöz ve Güler 2018). Çevrimiçi oyunlarla ilgili yapılan başka bir çalışmada da turizm pazarlamasında mobil çevrimiçi oyunların etkinliği incelenmiştir. Elsayeh (2020) tarafından yürütülen araştırmada Mısır'da turizm endüstrisi için bir reklam ve pazarlama aracı olarak mobil oyun reklamlarının etkisi incelenmiştir. Araştırma sonucunda çevrimiçi oyunların şehir markalaşmasında, turizm pazarlamasında ve şehir entegrasyonunda oldukça etkili oldu- 
ğunu tespit edilmiştir. Lacka (2020) tarafından yürütülen araştırmada ise artıılmış gerçekliğin oyunlarda kullanılmasının turizm pazarlamasına etkileri incelenmiştir. Araştırma ile birlikte oyuncuların artırılmış gerçeklik ile elde ettikleri deneyimlerin turizm hareketlerine katılma üzerinde etkili olduğu tespit edilmiştir. Özellikle şehirlerin ilgi çekici yerlerini sanal olarak deneyimleyen kişilerin bu bölgeleri gerçekte de ziyaret etmek istedikleri ortaya konulmuştur. Bu kapsamda da aşağıdaki hipotez geliştirilmiştir:

$H_{3}$ : Çevrimiçi oyunlardan elde edilen deneyimin tatil satın alma niyetine pozitif yönlü bir etkisi vardır.

Buradan hareketle, çevrimiçi oyunlara yönelik algının alt boyutları olan bağımlılık, iletişim ve deneyim faktörlerinin tatil satın almaya etkisini konu alan bir model belirlenmiştir (Şekil 1).

\section{YÖNTEM}

\section{Araştırmanın Amacı ve Önemi}

Alanyazın incelendiğinde çevrimiçi oyunların tüketicilerin tercihleri üzerinde etkili olduğu görülmüştür. Ayrıca alanyazında çevrimiçi oyunların seyahat motivasyonunu artırdığına yönelik çalışmalar da mevcuttur (Zeren ve Paylar 2016; Deleuze vd. 2017; Balakrishnan ve Griffiths 2018; Alagöz ve Güler 2018; Büyükbaykal ve Cansabuncu 2020; Elsayeh 2020; Shin, Jeong ve Park 2021). Bu araştırmada da çevrimiçi oyunların tatil satın alma niyetine etkilerinin incelenmesi amaçlanmıştır. Çevrimiçi oyunların tatil satın al-

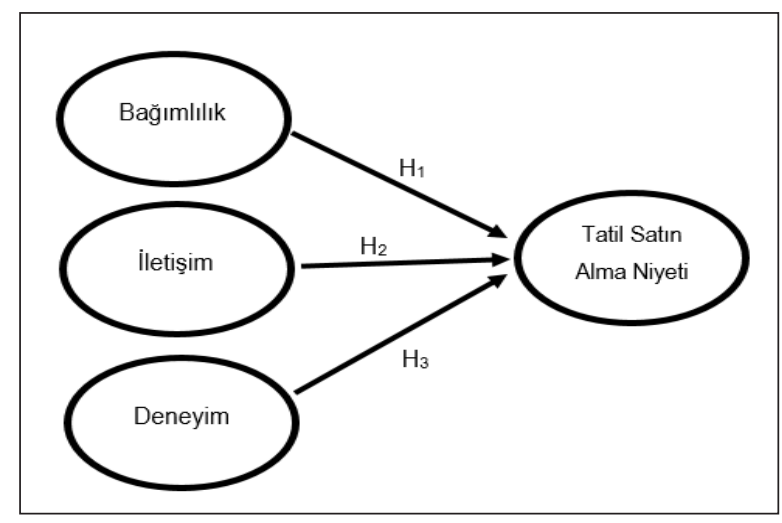

Şekil 1. Araştırma Modeli ma niyetine etkisi ile ilgili çok fazla çalışma yapılmamış olması ve çevrimiçi oyun piyasasının her geçen gün daha da büyüyen bir endüstri olması bu araştırmanın önemli olduğunu düşündürmektedir.

\section{Evren ve Örneklem}

Araştırmanın evrenini çevrimiçi oyun oynayan bireyler oluşturmaktadır. Bu kapsamda katılımcılara doğrudan ulaşabilmek adına 2021 yılının mart ayı boyunca Twitch internet kanalı ve Facebook uygulamasinda yer alan bir oyun grubu olan BGY: Games adlı mecralar üzerinden online anket formu paylaşılmıştır. 18 yaşın üzerinde olduğunu beyan eden ve gönüllü katılım gösteren 785 kişiye anket uygulanmıştır. Bunlardan eksiksiz olarak doldurulduğu tespit edilen 750 anket üzerinden veri seti oluşturulmuş ve araştırma analizleri yapılmıştır.

\section{Veri Toplama Yöntemi ve Aracı}

Araştırmada veri toplama yönetimi olarak anket tekniğinden yararlanılmıştır. Araştırmada kullanılan anket iki bölümden oluşmaktadır. Anketin ilk bölümde katılımcıların demografik özelliklerine yönelik ifadeler yer almaktadır. Anketin ikinci bölümde ise alanyazında yer alan çalışmalardan alınmış bir ölçek kullanılmıştır (Aymankuy, Soydaş ve Saçlı 2013; Balakrishnan ve Griffiths 2018; Dubois ve Gibbs 2018; Özhasar, Oğuz ve Yılmaz 2020). İlgili ölçek toplamda 16 ifadeden oluşan 5'li Likert tipinde (1: Hiç Katılmıyorum, 5: Tamamen Katıllyorum) derecelendirilmiş ifadelerden oluşmaktadır. Araştırma kapsamında kullanılan 16 ifadeli ölçeğin Cronbach's Alpha değeri 0,876 bulunmuştur. Bu değer kullanılan ölçeğin yüksek düzeyde güvenilir olduğunu göstermektedir. Ölçeğin geçerliliği ve güvenilirliği tespit edildikten sonra araştırmanın bulgular aşamasına geçilmiştir.

\section{BULGULAR}

Araştırmanın bulgular aşamasında katılımcıların cinsiyet, medeni durum, yaş, eğitim durumu, günlük ortalama oyunda geçirilen süre gibi tanımlayıcı istatistikler incelenmiştir. 
Tablo 1. Katılımcıların Özelliklerine Yönelik Bulgular

\begin{tabular}{|c|c|c|}
\hline Cinsiyet & Sayı (n) & Yüzde (\%) \\
\hline Kadın & 80 & 10,7 \\
\hline Erkek & 670 & 89,3 \\
\hline Medeni Durum & Sayı (n) & Yüzde (\%) \\
\hline Evli & 18 & 2,4 \\
\hline Bekâr & 732 & 97,6 \\
\hline Yaş & Sayı (n) & Yüzde (\%) \\
\hline $18-21$ yaş arası & 251 & 33,5 \\
\hline $22-25$ yaş arası & 323 & 43,1 \\
\hline $26-29$ yaş arası & 128 & 17,1 \\
\hline 30 yaş ve üzeri & 48 & 6,4 \\
\hline Eğitim Durumu & Sayı (n) & Yüzde (\%) \\
\hline İlköğretim Mezunu & 20 & 2,7 \\
\hline Lise Mezunu & 344 & 45,9 \\
\hline Üniversite Mezunu & 363 & 48,4 \\
\hline Lisansüstü Mezunu & 23 & 3,1 \\
\hline $\begin{array}{l}\text { Günlük Ortalama Oyunda } \\
\text { Geçirilen Süre }\end{array}$ & Sayı (n) & Yüzde (\%) \\
\hline 2 saatten az & 107 & 14,3 \\
\hline $2-4$ saat arası & 135 & 18 \\
\hline $4-6$ saat arası & 150 & 20 \\
\hline 6 saatten fazla & 358 & 47,7 \\
\hline Toplam & 750 & 100 \\
\hline
\end{tabular}

Tablo 1'de katılımcıların demografik özelliklerine yönelik bulgular yer almaktadır. Buna göre katılımcıların yüzde 89,3'ü (670) erkeklerden oluşmaktadır. Katılımcılar, medeni durum açısından incelendiğinde ise yüzde 97,6'sının (732) bekârlardan oluştuğu görülmüştür. Kat1lımcıların yaşlarına göre dağılımları incelendiğinde yüzde 43,1'i (323) 22 ile 25 yaş aralığında olduğu tespit edilmiştir. Araştırma kapsamında incelenen diğer bir demografik özellik ise eğitim durumudur. Buna göre katılımcıların yüzde 45,9'unun (344) lise mezunu, yüzde $48,4^{\prime}$ ü ise (363) üniversite mezundur. Bu hususta incelenen bir diğer veri de katılımcıların günlük ortalama oyun oynama süreleridir. Buna göre katılımcıların yüzde 14,3'ü (107) günde iki saatten az, yüzde 18 'i (135) günde ortalama iki ile dört saat arası, yüzde 20'si (150) günde ortalama dört ile altı saat arası ve yüzde $47,7^{\prime} \operatorname{sinin}(358)$ günde altı saatten daha fazla çevrimiçi oyun oynadığı görülmüştür.

\section{Faktör Analizi Bulguları}

Araştırmada faktör yapılarının belirlenmesi amacıyla toplanan verilere sırasıyla açıklayıcı ve doğrulayıcı faktör analizi yapılmıştır. Verilerin açılayıcı faktör analizine uygun olup olmadığını tespit edebilmek amacıyla KMO katsayısı ve Bartlett's testi bulguları incelenmiştir (KMO: 0,890 / Bartlett's: 0,00 ve $p<0,01)$. Her iki değerinde açıklayıcı faktör analizine uygun olduğu görülmüştür. Bu bağlamda da veri setini oluşturan 750 anket $375^{\prime}$ er olarak ikiye ayrılmıştır. Bu anketlerin ilk 375'i açılayıcı faktör analizinde diğer 375'i ise doğrulayıcı faktör analizinde kullanılmıştır.

Tablo 2'de yer alan açıklayıcı faktör analizinde bulguları incelendiğinde toplam varyansın yaklaşık yüzde 66'sını açıklayan dört faktörlü bir yapı tespit edilmiştir. Devamında bu dört faktörlü yapı araştırmanın amacına ve alanyazına göre; bağımlılık, iletişim, deneyim ve tatil satın alma niyeti şeklinde isimlendirilmiştir (Aymankuy, Soydaş ve Saçlı 2013; Balakrishnan ve Griffiths 2018; Dubois ve Gibbs 2018; Özhasar, Oğuz ve Y1lmaz 2020).

Açıklayıcı faktör analizinin devamında öncelikle araştırmanın bağımsız değişkenlerini oluşturan bağımlılık, iletişim ve deneyim boyutları üç faktörlü doğrulayıcı faktör analizine tabii tutulmuş ve ölçüm modeli doğrulanmıştır. Sonrasında ise araştırmanın bağımlı değişkeni olan tatil satın alma niyeti eklenerek tekrardan doğrulayıcı faktör analizi yapılmıştır. Devamında da yapılan doğrulayıcı faktör analizi alanyazında en çok kullanılan dokuz standart uyum ölçütüne göre değerlendirmeye alınmıştır.

Tablo 3'te yer alan bulgular incelendiğinde araştırma kapsamında önerilen modelin geçerli bir model olduğu belirlenmiştir. Diğer bir ifadeyle, açıklayıcı faktör analizi sonucu elde edilen dört faktörlü yapı doğrulanmıştır. Ancak burada birbiri ile güçlü bir korelasyon ilişkisi bulunduğu tespit edilen 11. ve 16. maddeler, modelden çıkartılmıştır. Araştırmanın devamında değiş̧kenler arası çoklu gizil ilişkilerin tespit edilmesi amacıyla yapısal eşitlik modellemesi aşamasına geçilmiştir (Çelik ve Yılmaz 2016). 
Tablo 2. Açıklayıcı Faktör Analizi Bulguları

\begin{tabular}{|c|c|c|c|c|}
\hline ifadeler & $\begin{array}{l}\text { Faktör } \\
\text { Yükü }\end{array}$ & $\begin{array}{l}\text { Açıklanan } \\
\text { Varyans }\end{array}$ & Özdeğer & Güvenilirlik \\
\hline \multicolumn{5}{|l|}{ Bağımlılık } \\
\hline $\begin{array}{l}\text { Çevrimiçi oyunlarda çok zaman } \\
\text { geçirdiğimden dolayı bazı zamanlarda } \\
\text { işlerimi aksatıyorum. }\end{array}$ & 0,781 & 35,710 & 5,714 & 0,744 \\
\hline $\begin{array}{l}\text { Çevrimiçi oyun oynamayı gerçek dünyadan } \\
\text { bir kaçış olarak görüyorum. }\end{array}$ & 0,723 & & & \\
\hline $\begin{array}{l}\text { Çevrimiçi oyun oynarken kendimi özgür } \\
\text { hissediyorum. }\end{array}$ & 0,699 & & & \\
\hline $\begin{array}{l}\text { Sabah uyandığımda aklımda hep çevrimiçi } \\
\text { oyun oynamak olur. }\end{array}$ & 0,582 & & & \\
\hline \multicolumn{5}{|l|}{ Iletişim } \\
\hline $\begin{array}{l}\text { Arkadaşlarımla iletişim halinde olabilmek } \\
\text { için daha uzun süre çevrimiçi oyun } \\
\text { oynarım. }\end{array}$ & 0,796 & 6,271 & 1,003 & 0,737 \\
\hline $\begin{array}{l}\text { Çevrimiçi oyunlarda bağlantı kurduğum } \\
\text { insanlara kendimi daha iyi anlatıyorum. }\end{array}$ & 0,718 & & & \\
\hline $\begin{array}{l}\text { Çevremde birileri varken bile çevrimiçi } \\
\text { oyun oynamayı tercih ederim. }\end{array}$ & 0,559 & & & \\
\hline
\end{tabular}

\section{Deneyim}

Çevrimiçi oyunlarda kullanılan gerçek mekânlar dikkatimi çeker.

0,756

Çevrimiçi oyunlarda kullanılan gerçek

\section{0,756}

mekânlardan etkilenirim.

Çevrimiçi oyun oynarken zamanın nasıl

geçtiğini anlamıyorum.

0,634

Kendimi mutsuz hissettiğim zamanlarda çevrimiçi oyun oynamak beni rahatlatır.

\section{Satın alma niyeti}

Çevrimiçi oyunlarda kullanılan mekânları

ziyaret etmek için tatil planlarımı

değiştirebilirim.

Çevrimiçi oyunlarda kullanılan gerçek

mekânlar tatil satın alma kararımı etkiler.

Çevrimiçi oyunlarda kullanılan gerçek

mekânlar tatil satın alma kararıma

yardımcı olur.

Çevrimiçi oyunlarda kullanılan mekânları

ziyaret etmek için mutlaka fırsat yaratırım.

Çevrimiçi oyunlarda gördüğüm gerçek bir mekânı ziyaret etmeyi düşünüyorum. 
Tablo 3. Önerilen Modelin Standart Uyum Ölçütlerine Göre Değerlendirilmesi

\begin{tabular}{ccccc}
\hline Uyum Ölçütleri & ìyi Uyum & Kabul Edilebilir Uyum & Model & Uyum \\
& & & Değeri & \\
\hline $\mathrm{x}^{2} / \mathrm{sd}$ & $0 \leq \mathrm{x}^{2} / \mathrm{sd}<2$ & $2 \leq \mathrm{x}^{2} / \mathrm{sd} \leq 5$ & 3,00 & Kabul Edilebilir \\
RMSEA & $0 \leq \mathrm{RMSEA}<0,05$ & $0,05 \leq \mathrm{RMSEA} \leq 0,10$ & 0,067 & Kabul Edilebilir \\
SRMR & $0 \leq \mathrm{SRMR}<0,05$ & $0,05 \leq \mathrm{SRMR} \leq 0,10$ & 0,042 & İyi Uyum \\
$\mathrm{NFI}$ & $0,95<\mathrm{NFI} \leq 1,00$ & $0,90 \leq \mathrm{NFI} \leq 0,95^{\mathrm{a}}$ & 0,96 & İyi Uyum \\
$\mathrm{NNFI}$ & $0,97<\mathrm{NNFI} \leq 1,00$ & $0,95 \leq \mathrm{NNFI} \leq 0,97^{\mathrm{b}}$ & 0,98 & İyi Uyum \\
IFI & $0,95<\mathrm{IFI} \leq 1,00$ & $0,90 \leq \mathrm{IFI} \leq 0,95$ & 0,97 & İyi Uyum \\
RFI & $0,95<\mathrm{RFI} \leq 1,00$ & $0,90 \leq \mathrm{RFI} \leq 0,95$ & 0,96 & İyi Uyum \\
CFI & $0,97<\mathrm{CFI} \leq 1,00$ & $0,95 \leq \mathrm{CFI} \leq 0,97$ & 0,98 & İyi Uyum \\
GFI & $0,95<\mathrm{GFI} \leq 1,00$ & $0,90 \leq \mathrm{GFI} \leq 0,95$ & 0,94 & Kabul Edilebilir \\
AGFI & $0,90<\mathrm{AGFI} \leq 1,00$ & $0,85 \leq \mathrm{AGFI} \leq 0,90$ & 0,92 & İyi Uyum
\end{tabular}

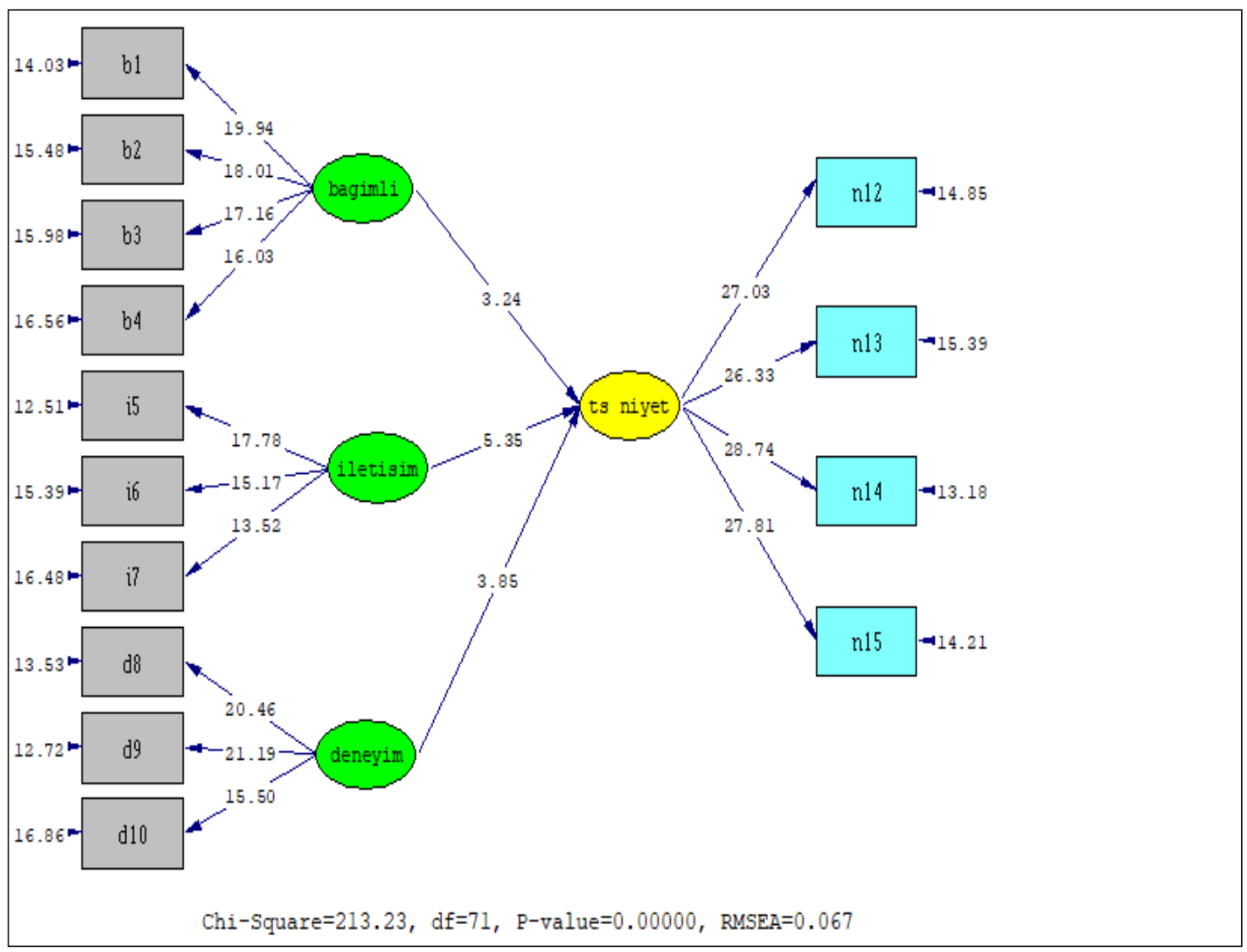

Tablo 3. Önerilen Modelin Standart Uyum Ölçütlerine Göre Değerlendirilmesi 
Yasin Emre Oğuz - Mustafa Çağatay Kızıltaş - Veysel Yılmaz

Tablo 4. Araştırma Hipotezlerinin Değerlendirilmesi

\begin{tabular}{|c|c|c|c|c|c|}
\hline Faktörler & $\begin{array}{l}\text { Standart } \\
\text { Yükler }\end{array}$ & t-değeri & $R^{2}$ & $\begin{array}{c}\text { Yapı } \\
\text { Güvenilirliği }\end{array}$ & $\begin{array}{c}\text { Açıklanan } \\
\text { Varyans (AVE) }\end{array}$ \\
\hline Bağımlııık & & & & 0,82 & 0,53 \\
\hline \multirow[t]{4}{*}{ (B) } & 0,71 & $19,94 * * *$ & 0,50 & & \\
\hline & 0,66 & $18,01 * * *$ & 0,44 & & \\
\hline & 0,63 & $17,16 * * *$ & 0,40 & & \\
\hline & 0,60 & $16,03 * * *$ & 0,36 & & \\
\hline İletişim & & & & 0,74 & 0,49 \\
\hline \multirow[t]{3}{*}{ (i) } & 0,69 & $17,78^{* * *}$ & 0,48 & & \\
\hline & 0,60 & $15,17 * * *$ & 0,36 & & \\
\hline & 0,54 & $13,52 * * *$ & 0,29 & & \\
\hline Deneyim & & & & 0,82 & 0,60 \\
\hline \multirow[t]{3}{*}{ (D) } & 0,73 & $20,46 * * *$ & 0,53 & & \\
\hline & 0,75 & $21,19 * * *$ & 0,56 & & \\
\hline & 0,58 & $15,50 * * *$ & 0,34 & & \\
\hline \multirow{5}{*}{$\begin{array}{l}\text { Tatil Satın Alma } \\
\text { (TSA) }\end{array}$} & & & & 0,91 & 0,71 \\
\hline & 0,83 & $27,03 * * *$ & 0,69 & & \\
\hline & 0,82 & $26,33 * * *$ & 0,67 & & \\
\hline & 0,87 & $28,74 * * *$ & 0,75 & & \\
\hline & 0,85 & $27,81 * * *$ & 0,72 & & \\
\hline Hipotezler & & \multicolumn{4}{|c|}{ Sonuç } \\
\hline $\mathrm{H} 1: \mathrm{B} \rightarrow \mathrm{TSA}$ & 0,28 & $3,24 * * *$ & \multicolumn{2}{|r|}{ Desteklendi } & \\
\hline $\mathrm{H} 2: \mathrm{i} \rightarrow \mathrm{TSA}$ & 0,42 & $5,35 * * *$ & \multicolumn{2}{|r|}{ Desteklendi } & \\
\hline H3: $D \rightarrow T S A$ & 0,33 & $3,85^{* * *}$ & \multicolumn{2}{|r|}{ Desteklendi } & \\
\hline
\end{tabular}

\section{Yapısal Eşitlik Modellemesi Bulguları}

Şekil 2'de araştırma kapsamında önerilen modelin ve kurulan hipotezlerin test edilmesi amaciyla yapılan yapısal eşitlik modellemesi bulguları yer almaktadır. Analizde yer alan $t$ değerleri incelendiğinde araştırma modeli kabul edilmiştir $(t>1,96 ; p<0,050)$. Analizin son aşamasında modelin yapı güvenilirliği, açıklanan varyansı incelenmiş ve hipotezler değerlendirilmiştir.

Tablo 4 incelendiğinde araştırma kapsamında kurulan üç hipotezin de desteklendiği görülmüştür. Buna göre bağımlılık, iletişim ve deneyim değişkenleri tatil satın alma niyetine istatistiksel olarak anlamlı ve pozitif yönlü olarak etkilemektedir.

\section{SONUÇ VE ÖNERILER}

Küreselleşen sosyal medya ile bağıntılı olarak eğlence endüstrisi de sürekli bir gelişim göstermektedir. Çevrimiçi oyunlar ise bu sürekli gelişim gösteren pazarın önemli bir dinamiğini oluşturmaktadır. Güncel verilere göre 2,6 milyar kullanıcısı olan, 2021 yılında 23,5 milyar dolarlık hacme ulaşacağ 1 tahmin edilen ve her geçen yıl daha da değer kazanan çevrimiçi oyun endüstrisi bilimsel anlamda da önem kazanmaya ve araştırmacıların yoğun ilgisini çekmeye başlamıştır (Statista 2020).

Yapılan bu araştırma kapsamında çevrimiçi oyun oyuncularının oynadıkları oyunlara yöne- 
lik algılarının üç alt faktörü olarak belirlenen iletişim, deneyim ve bağımlılık değişkenlerinin tatil satın alma aşamasında destinasyon tercihlerine olan etkisi yapısal eşitlik modellemesi ile incelenmiştir. Yapılan analiz sonucunda ilgili üç faktörün de tatil satın alma niyeti üzerinde istatistiksel olarak anlamlı ve pozitif yönlü olarak etkisi olduğu tespit edilmiştir. Bu bağlamda yapılan araştırma mevcut alanyazında yer alan çalışmaları destekler niteliktedir (Zeren ve Paylar 2016; Deleuze vd. 2017; Dubois ve Gibbs 2018; Balakrishnan ve Griffiths 2018; Alagöz ve Güler 2018; Büyükbaykal ve Cansabuncu 2020; Elsayeh 2020; Lacka 2020; Shin, Jeong ve Park 2021).

Araştırmada tatil satın alma niyetini en çok etkileyenin iletişim faktörü olduğu görülmüştür. İletişim faktörünün bu kadar yüksek çıkmasının temel nedenlerinden birinin de pandemi süreci olduğu düşünülmektedir. Covid-19 nedeniyle sekteye uğrayan sosyalleşmenin özellikle çevrimiçi oyun endüstrisine önemli katkıları olmuştur. Araştırmanın diğer egzojen değişkenleri olan bağımlılık ve deneyimin araştırmanın endojen değişkeni tatil satın alma niyeti üzerinde istatistiksel olarak anlamlı etkileri olduğu görülmüştür. Çevrimiçi oyunlarda kullanılan gerçek veya gerçeğinden ilham alınmış mekânların yarattığ deneyim hissinin de tatil satın alma niyet üzerinde önemli etkileri olduğu görülmüştür. $\mathrm{Bu}$ durum turizm destinasyonu karar vericilerinin üzerinde durması gereken bir konuya işaret etmektedir. Özellikle çevrimiçi oyunlara yönelik yapılacak sponsorluk yatırımları ile ülkelerin ve destinasyonların tanıtımının yapılabileceği düşünülmektedir.

Araştırma sonuçlarına dayanarak, büyük bir kitleye hitap eden çevrimiçi oyunların turizm pazarlaması açısından büyük bir fırsat olduğu söylenebilir. Dünyanın her yerinden insanlara hitap eden bu oyunların turizm sektörü tarafından reklam amaçlı kullanılmasının da faydalı olacağı düşünülmektedir. İleride yapılacak olan çalışmalarda bu çalışma kapsamında önerilen modele farklı değişkenlerin eklenmesinin veya düzenleyicilik ve aracılık etkilerine bakılmasının da mevcut alanyazına katkı sağlayacağı düşünülmektedir.

\section{KAYNAKÇA}

Adamus, T. (2012). Playing Computer Games as Electronic Sport: In Search of a Theoretical Framework for a New Research Field. İçinde; J. Fromme ve A. Unger (Editörler) Computer Games and New Media Cultures (ss. 477490). Dordrecht: Springer.

Alagöz, S. ve Güler, B. (2018). Bilgisayar Oyunlarında Ürün Yerleştirmeye Yönelik Tüketici Tutumu ve Satın Alma Niyeti Arasındaki İlişki, Kahramanmaraş Sütçü İmam Üniversitesi Sosyal Bilimler Dergisi, 15 (2): 479- 500.

Aymankuy, Y., Soydaş, M.E. ve Saçlı, Ç. (2013). Sosyal Medya Kullanımının Turistlerin Tatil Kararlarına Etkisi: Akademik Personel Üzerinde Bir Uygulama, International Journal of Human Sciences, 10 (1): 376- 397.

Badrinarayanan, V., Sierra, J. ve Martin, K. (2015). A Dual Identification Framework of Online Multiplayer Video Games: The Case Of Massively Multiplayer Online Role Playing Games (MMORPGs), Journal of Business Research, 68 (5): 1045- 4052.

Balakrishnan, J. ve Griffiths, M. (2018). Loyalty Towards Online Games, Gaming Addiction, and Purchase Intention Towards Online Mobile in Game Features, Computers in Human Behavior, 87: 238- 246.

Buhalis, D. ve Law, R. (2008). Progress in Information Technology and Tourism Management: 20 Years on and 10 years After the Internet - The State of eTourism Research, Tourism Management, 29 (4): 609- 623.

Büyükbaykal, C. I. ve Cansabuncu, İ. A. (2020). Türkiye'de Yeni Medya Ortamı ve Dijital Oyun Olgusu, Yeni Medya Elektronik Dergisi, 4 (1): 1- 9.

Chen, L. L. (2010). The Impact of Perceived Risk, Intangibility and Consumer Characteristics on Online Game Playing, Computers in Human Behavior, 26 (6): 1607- 1613.

Chen, T. (2015). Online Games, Computers in Entertainment, 11 (4): 1- 26.

Choi, B., Lee, I., Choi, D. ve Kim, J. (2007). Collaborate and Share: An Experimental Study of the Effects of Task and Reward Interdependencies in Online Games, CyberPsychology \& Behavior, 10 (4): 591- 595.

Deleuze, J., Christiaens, M., Nuyens, F. ve Billieux, J. (2017). Shoot at first sight! First Person Shooter Players Display Reduced Reaction Time and Compromised Inhibitory Control in Comparison to Other Video Game Players, Computers in Human Behavior, 72: 570- 576.

Dindar, M. ve Akbulut, Y. (2014). Motivational Characteristics of Turkish MMORPG Players, Computers in Human Behavior, 33: 119- 125.

Dubois, L. E. ve Gibbs, C. (2018). Video Game Induced Tourism: A New Frontier for Destination Marketers, Tourism Review, 73 (2): 186- 198.

Elsayeh, Y. (2020). Investigating the Effectiveness of Applying Mobile Advergames in Tourism Marketing - An Exploratory Study about Egypt, International Journal of Research in Tourism and Hospitality, 6 (2): 21-32.

Funk, D., Pizzo, A. ve Baker, B. (2018). Esport management: Embracing Esport Education and Research Opportunities, Sport Management Review, 21 (1): 7- 13. 


\section{Yasin Emre Oğuz - Mustafa Çağatay Kızıltaş - Veysel Yılmaz}

Gong, X., Zhang, K., Chen, C., Cheung, C. ve Lee, M. (2020). Antecedents and Consequences of Excessive Online Social Gaming: a Social Learning Perspective, Information Technology \& People, 33 (2): 667- 688.

Gray, P., Vuong, J., Zava, D. ve McHale, T. (2018). Testing Men's Hormone Responses to Playing League of Legends: No Changes in Testosterone, Cortisol, DHEA Or Androstenedione But Decreases in Aldosterone, Computers in Human Behavior, 83: 230- 234.

Hamari, J. ve Sjöblom, M. (2017). What is E-sports and Why Do People Watch It?, Internet Research, 27 (2): 211- 232.

Hsu, C. L. ve Lu, H.P. (2004). Why Do People Play Online Games: An Extended TAM with Social Influences and Flow Experience, Information \& Management, 41 (7): 853- 868.

Hsu, S., Wen, M. H. ve Wu, M. C. (2009). Exploring User Experiences as Predictors of MMORPG Addiction, Computers \& Education, 53 (3): 990- 999.

Hussain, Z., Williams, G. ve Griffiths, M. (2015). An Exploratory Study of the Association between Online Gaming Addiction and Enjoyment Motivations for Playing Massively Multiplayer Online Role Playing Games, Computers in Human Behavior, 50: 221- 230.

Hyeong, J., Choi, K., Lee, J. ve Pyo, T. H. (2020). For Whom Does a Game Update: Players' Status Contingent Gameplay on Online Games Before and After an Update, Decision Support Systems, 139: 1- 11.

Jonasson, K. ve Thiborg, J. (2010). Electronic Sport and Its Impact on Future Sport, Sport in Society, 13 (2): 287- 299.

Kindermann, H., Javor, A. ve Reuter, M. (2016). Playing Counter Strike Versus Running: The Impact of Leisure Time Activities and Cortisol on Intermediate Term Memory in Male Students, Cognitive Systems Research, 40: 1-7.

Lacka, E. (2020). Assessing the Impact of Full-Fledged Location-Based Augmented Reality Games on Tourism Destination Visits, Current Issues in Tourism, 23 (3): 345- 357.

Lee, M. C. (2009). Understanding the Behavioural Intention to Play Online Games: An Extension of the Theory of Planned Behaviour, Online Information Review, 33 (5): 849- 872.

Lee, S., Suh, Y., Kim, J. ve Lee, K. (2004). A Cross-national Market Segmentation of Online Game Industry Using SOM, Expert Systems with Applications, 27 (4): 559- 570.

Liao, G. Y., Pham, T., Cheng, T. ve Teng, C. I. (2020). How Online Gamers' Participation Fosters Their Team Commitment: Perspective of Social Identity Theory, International Journal of Information Management, 52: 1- 12.
Meagher, K. ve Teo, E. (2005). Two-part Tariffs in the Online Gaming Industry: The role of Creative Destruction and Network Externalities, Information Economics and Policy, 17 (4): 457- 470.

Özhasar, Y., Oğuz, Y.E. ve Yılmaz, V. (2020). Instagram Bağımlılığının Tatil Satın Alma Niyetine Etkisi: Esogü Turizm Fakültesi Öğrencileri Örneği, Safran Kültür ve Turizm Araştırmaları Dergisi, 3 (1): 39- 55.

Peng, H., Sun, Y. ve Wu, H. (2009). Analysis of Subscription Characteristics and User Mobility in Different Types of MMORPGs, The Journal of China Universities of Posts and Telecommunications, 16 (6): 121- 128.

Pietro, L. ve Pantano, E. (2013). Social Network Influences on Young Tourists: An Exploratory Analysis of Determinants of the Purchasing Intention, Journal of Direct, Data and Digital Marketing Practice, 15: 4- 19.

Reer, F. ve Krämer, N. (2014). Underlying Factors of Social Capital Acquisition in the Context of Online Gaming: Comparing World of Warcraft and Counter Strike, Computers in Human Behavior, 36: 179- 189.

Shin, S.J., Jeong, D., ve Park, E. (2021). Effects of Conflicts On Outcomes: The Case of Multiplayer Online Games, Entertainment Computing, 38: 1- 5.

Statista. (2020). Online Games, https://www.statista.com/outlook/212/100/online-games/worldwide, Erişim tarihi: 27 Aralık 2020.

Teng, C. I. (2017). Impact of Avatar Identification on Online Gamer Loyalty: Perspectives of Social Identity and Social Capital Theories, International Journal of Information Management, 37 (6): 601- 610.

Trepte, S., Reinecke, L. ve Juechems, K. (2012). The Social Side of Gaming: How Playing Online Computer Games Creates Online and Offline Social Support, Computers in Human Behavior, 28 (3): 832- 839.

Wu, P., Yeh, G. Y. ve Hsiao, C. R. (2011). The Effect of Store Image and Service Quality on Brand Image and Purchase Intention for Private Label Brands, Australasian Marketing Journal, 19 (1): 30- 39.

Yung, R. ve Khoo-Lattimore, C. (2019). New Realities: A Systematic Literature Review on Virtual Reality and Augmented Reality in Tourism Research, Current Issues in Tourism, 22 (17): 2056- 2081.

Zeren, D. ve Paylar, Ö. (2016). Bilgisayar Oyunlarında Ürün Yerleştirme: Pro Evolution Soccer (Pes) 2015 Örneği, Online Academic Journal of Information Technology, 7 (24): 51- 67. 


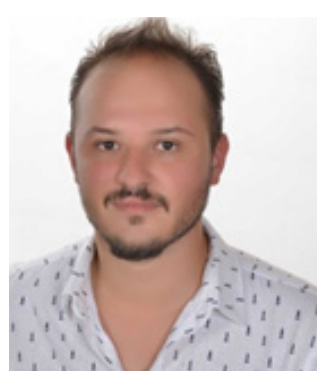

Yasin Emre OĞUZ

Trakya Üniversitesi Uygulamalı Bilimler Fakültesi Turizm İ̧̧letmeciliği ve Otel Yönetimi Bölümü'nden mezun oldu (2013). Yüksek lisans derecesini Eskişehir Osmangazi Üniversitesi Sosyal Bilimler Enstitüsü Turizm İsletmeciliği Anabilim Dalı'ndan aldı (2017). Halen Eskişehir Osmangazi Üniversitesi Sosyal Bilimler Enstitüsü Turizm İ̧̧letmeciliği Anabilim Dalı’nda Doktora eğitimine devam etmektedir. 2014 yılında Eskişehir Osmangazi Üniversitesi'nde Araştırma Görevlisi olarak çalışmaya başladı. Halen Eskişehir Osmangazi Üniversitesi Turizm Fakültesi'nde görev yapmaktadır. Temel çalışma alanları, turizm ekonomisi ve nicel araştırma yöntemleridir.

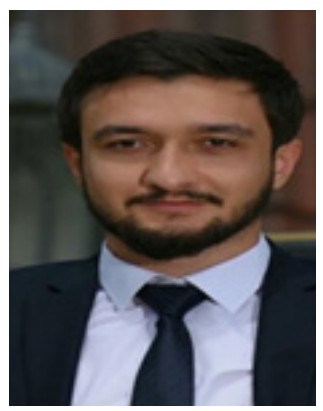

\section{Mustafa Çağatay KIZILTAŞ}

Necmettin Erbakan Üniversitesi Turizm Fakültesi Turizm İşletmeciliği Bölümü'nden mezun oldu (2017). Yüksek lisans derecesini Eskişehir Osmangazi Üniversitesi Sosyal Bilimler Enstitüsü Turizm İşletmeciliği Anabilim Dalı'ndan aldı (2019). Halen Eskişehir Osmangazi Üniversitesi Sosyal Bilimler Enstitüsü Turizm İşletmeciliği Anabilim Dalı́nda Doktora eğitimine devam etmektedir. Sivas Cumhuriyet Üniversitesi'nde Öğretim Görevlisi olarak çalışmaya başladı (2020). Halen Sivas Cumhuriyet Üniversitesi Divriği Nuri Demirağ Meslek Yüksekokulu'nda Otel, Lokanta ve İkram Hizmetleri Bölümü’nde görev yapmaktadır. Temel çalışma alanları, turizm işletmeciliği ve nicel araştırma yöntemleridir.

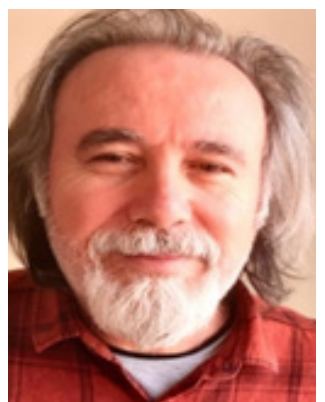

\section{Veysel YILMAZ}

Anadolu Üniversitesi Fen Edebiyat Fakültesi İstatistik Bölümü'nden mezun oldu (1988). Yüksek lisans derecesini Anadolu Üniversitesi Fen Bilimleri Enstitüsü İstatistik Anabilim Dalı́ndan aldı (1992). Doktora derecesini Eskişehir Osmangazi Üniversitesi Fen Bilimleri Enstitüsü İstatistik Anabilim Dalı́ndan aldı (1996). Anadolu Üniversitesi'nde Araştırma Görevlisi olarak çalışmaya başladı (1990). Eskişehir Osmangazi Üniversitesi'nde Yardımcı Doçent olarak çalışmaya başladı (1996). Doçent unvanını 2005, Profesör unvanını 2011 yılında aldı. Halen Eskişehir Osmangazi Üniversitesi Fen Edebiyat Fakültesi'nde görev yapmaktadır. Temel çalışma alanları, istatistik ve nicel araştırma yöntemleridir. 